\title{
Mesocortical Dopamine Neurons Operate in Distinct Temporal Domains Using Multimodal Signaling
}

\author{
Antonieta Lavin, ${ }^{1 \star}$ Lourdes Nogueira, ${ }^{1 \star}$ Christopher C. Lapish, ${ }^{1 \star}$ R. Mark Wightman, ${ }^{2}$ Paul E. M. Phillips,${ }^{3}$ and \\ Jeremy K. Seamans ${ }^{1}$ \\ ${ }^{1}$ Department of Physiology and Neuroscience, Medical University of South Carolina, Charleston, South Carolina 29425, 2Department of Chemistry, \\ University of North Carolina, Chapel Hill, North Carolina 27599, and ${ }^{3}$ Department of Psychiatry and Behavioral Sciences and Department of Pharmacology, \\ University of Washington, Seattle, Washington 98195
}

In vivo extracellular recording studies have traditionally shown that dopamine (DA) transiently inhibits prefrontal cortex (PFC) neurons, yet recent biophysical measurements in vitro indicate that DA enhances the evoked excitability of PFC neurons for prolonged periods. Moreover, although DA neurons apparently encode stimulus salience by transient alterations in firing, the temporal properties of the PFC DA signal associated with various behaviors is often extraordinarily prolonged. The present study used in vivo electrophysiological and electrochemical measures to show that the mesocortical system produces a fast non-DA-mediated postsynaptic response in the PFC that appears to be initiated by glutamate. In contrast, short burst stimulation of mesocortical DA neurons that produced transient $(<4 \mathrm{~s}) \mathrm{DA}$ release in the PFC caused a simultaneous reduction in spontaneous firing (consistent with extracellular in vivo recordings) and a form of DA-induced potentiation in which evoked firing was increased for tens of minutes (consistent with in vitro measurements). We suggest that the mesocortical system might transmit fast signals about reward or salience via corelease of glutamate, whereas the simultaneous prolonged DA-mediated modulation of firing biases the long-term processing dynamics of PFC networks.

Key words: prefrontal cortex; dopamine tone; ventral tegmental area; glutamate; in vivo recordings; reward

\section{Introduction}

The ventral tegmental area (VTA) provides dopamine (DA) to the prefrontal cortex (PFC), and release of DA from midbrain neurons has been characterized as tonic or phasic (Grace, 2002). Microdialysis measures have shown that tonic DA levels exist in the PFC that are in the low nanomolar range (Hedou et al., 2001; Marsteller et al., 2002), but extracellular DA levels can increase many fold above this baseline for tens of minutes. These longlasting changes in DA levels do not differentiate between the motivational valence of events, because increases in PFC DA occur as robustly to unexpectedly rewarding stimuli as to aversive stimuli (Feenstra et al., 1995, 2000; Feenstra and Botterblom, 1996; Taber and Fibiger, 1997; Watanabe et al., 1997; Ahn and Phillips, 1999; Phillips et al., 2004). In contrast, the firing patterns of VTA neurons have been suggested to encode temporally precise information about reward, reward predictions, or stimulus salience (Miller et al., 1981; Rasmussen et al., 1986; Freeman and Bunney, 1987; Schultz, 1997, 1998).

Received Dec. 29, 2004; revised April 12, 2005; accepted April 13, 2005

This work was supported by grants from the National Institute of Mental Health (MH65924 and MH064569 to J.K.S.), National Alliance for Research on Schizophrenia and Depression (J.K.S.), National Science Foundation (83891 to C.C.L.), and National Institute on Drug Abuse (14698 to A.L.). We thank Laurence Neely for technical assistance and Drs. Sven Kroener and Susan Sesack for helpful discussions.

${ }^{*}$ A.L., L.N., and C.C.L. contributed equally to this work.

Correspondence should be addressed to Dr. Jeremy K. Seamans, Department of Physiology and Neuroscience, Medical University of South Carolina, 173 Ashley Avenue, Suite 403, Charleston, SC 29425. E-mail: seamans@musc.edu.

DOI:10.1523/JNEUROSCI.0557-05.2005

Copyright $\odot 2005$ Society for Neuroscience $\quad$ 0270-6474/05/255013-11\$15.00/0
Voltammetric measurements have revealed that transient burst activation of VTA DA neurons effectively evokes phasic release of DA in the PFC (Garris et al., 1993). Brief VTA stimulation evokes a transient ( $\sim 200 \mathrm{~ms})$ inhibition of PFC neurons recorded extracellularly in vivo (Bunney and Aghajanian, 1976; Sesack and Bunney, 1989; Godbout et al., 1991; Pirot et al., 1992). Although this phasic inhibition is typically blocked by DA antagonists, such antagonists would also eliminate tonic DA modulation of PFC neurons. Furthermore, the transient inhibition typically begins within $\sim 20 \mathrm{~ms}$ of VTA stimulation, which corresponds approximately to the peak of an EPSP, and therefore is barely enough time for activation of ionotropic receptors, let alone modulation of an input by DA receptors that are metabotropic in the PFC. Therefore, certain issues remain regarding the classical view of transient inhibition in the PFC by the VTA.

Brief DA elevations can also exert prolonged actions. Williams and Millar (1990) reported that stimulation of the medial forebrain bundle (MFB) that evoked DA levels of $<1 \mu \mathrm{M}$ caused an elevation in the firing of nearby striatal neurons that outlasted the period of stimulation by as much as $300 \mathrm{~s}$. There is reason to believe that the effects of DA may produce even more prolonged effects in the PFC, given the fact that evoked DA levels decay at a much slower rate in the PFC (Garris et al., 1993; Cass and Gerhardt, 1995), mainly because of the much lower concentrations of the DA transporter (DAT) (Sesack et al., 1998; Moron et al., 2002). Accordingly, bath application of DA (2-5 min) has been shown to exert prolonged ( $>30 \mathrm{~min}$ ) increases in various intrinsic or synaptic currents in PFC interneurons (Gorelova et al., 
2002) and pyramidal neurons (Yang and Seamans, 1996; Gorelova and Yang, 2000; Henze et al., 2000; Gulledge and Jaffe, 2001; Seamans et al., 2001a,b), similar to the prolonged effects of DA observed in other neuron types (Gribkoff and Ashe, 1984; Huang and Kandel, 1995; Umemiya and Raymond, 1997; Yang, 2000; Seamans and Yang, 2004). Yet, the in vitro preparation lacks endogenous DA tone, and DA is often applied in high concentrations for minutes, which is much longer than the elevation in phasic DA levels that normally lasts for seconds (Garris et al., 1993). Therefore, if one is to find evidence for a system capable of transferring a transient signal to the $\mathrm{PFC}$, in vivo experiments investigating the effects of phasic DA activation on PFC neurons are required.

The goal of the present study was to investigate the signal conveyed to PFC neurons by activation of mesocortical DA neurons. Field recordings or intracellular recordings from deep-layer PFC neurons were made before and after transient burst activation of the VTA. Voltammetric analyses assessed the duration and magnitude of stimulus-induced elevations in extrasynaptic DA levels. Results indicate that a non-DA signal elicits fast PSPs in PFC neurons, whereas a DA-mediated signal modulates the excitability of PFC neurons for prolonged periods.

\section{Materials and Methods \\ Electrophysiology}

In vivo field potentials. Forty-five male Sprague Dawley rats (250-300 g; Charles River Laboratories, Wilmington, MA) were anesthetized with 1.5 $\mathrm{g} / \mathrm{kg}$ urethane or a ketamine/xylazine mixture $(20: 6 \mathrm{mg} / \mathrm{kg})$ and placed into a Narishige (Tokyo, Japan) stereotaxic device. Supplemental injections were delivered as needed to maintain an adequate level of anesthesia. The cisterna magna was drained, the skull was drilled, and the dura was resected over the PFC [anteroposterior $(\mathrm{A} / \mathrm{P}),+3.2$; mediolateral $(\mathrm{M} / \mathrm{L}), \pm 1.2$; dorsoventral $(\mathrm{D} / \mathrm{V}),-3.0 ; 10^{\circ}$ angle from the sagittal plane], the VTA $\left(\mathrm{A} / \mathrm{P},+6.6 ; \mathrm{M} / \mathrm{L}, \pm 0.7 ; \mathrm{D} / \mathrm{V},-8.2 ; 10^{\circ}\right.$ angle from the coronal plane), or the MFB $(\mathrm{A} / \mathrm{P},-0.2 ; \mathrm{M} / \mathrm{L},-1.8 ; \mathrm{D} / \mathrm{V},-8.8)$. A concentric bipolar stimulating electrode (World Precision Instruments, Sarasota, FL) glued to a glass puffer pipette ( $\sim 20 \mu \mathrm{m}$ open tip) was lowered into the VTA. A 2 M NaCl-filled glass pipette pulled on a Flaming/Brown P97 horizontal puller was lowered into the PFC (open tip resistance, $1-2 \mathrm{M} \Omega$ ). Test pulses were given, and fine spatial adjustment of electrodes was performed to optimize field responses. Field responses were amplified by an NPI Instruments (Tamm, Germany) SEC-05LX amplifier, filtered at $1 \mathrm{kHz}$, and digitized by a National Instruments (Austin, TX) PCMCIO 16E4 board connected to a personal computer running custom Labview software (Lee Campbell, Salk Institute, La Jolla, CA).

Given the stability of field recordings, reverse dialysis could be performed easily, as opposed to in vivo intracellular recordings in which systemic administration of drugs was more practical. After field responses were established, dialysis probes (CMA 11, CMA Solna, and Sweden) were lowered within $1 \mathrm{~mm}$ of the pipette. The location of the dialysis probe with respect to the recording pipette was verified histologically in fixed sections. Reverse dialysis was performed via a CMA 102 pump (CMA, Solna, and Sweden) at a rate of $2 \mu \mathrm{l} / \mathrm{min}$. After the dialysis probe was lowered and an initial field response was isolated, $2 \mathrm{~h}$ were given before experiments commenced to allow for tissue acclimation to the microdialysis probe and recording pipette. During this period, the VTA was stimulated via a World Precision Instruments A360 stimulator at various intervals to assess the continued reliability of the VTA-evoked response. After verifying the stability of the response with the dialysis probe in place, the VTA was stimulated every $30 \mathrm{~s}$, and baseline recordings were obtained for a minimum of $30 \mathrm{~min}$.

Pharmacological manipulation of the PFC was then performed via reverse dialysis of the AMPA/kainate receptor antagonist 6-cyano-7nitroquinoxaline-2,3-dione disodium salt (CNQX) $(5 \mu \mathrm{M})$, the $\mathrm{GABA}_{\mathrm{A}}$ receptor antagonist bicuculline (10 $\mu \mathrm{M}$; Sigma, St. Louis, $\mathrm{MO})$, and the $\mathrm{D}_{1}$ antagonist 7-chloro-8-hydroxy-3-methyl-5-phenyl-2,3,4,5-tetrahydro- $1 \mathrm{H}$ 3-benzazepine ( $\mathrm{SCH} 23390)$ or the $\mathrm{D}_{2}$ antagonist sulpiride (both from
Sigma) via a CMA 110 liquid switch. Reverse dialysis of artificial CSF (ACSF) occurred continuously during these experiments. Glutamate $(0.25-1 \mathrm{mM}$ L-glutamic acid; Sigma) was applied focally for $50 \mathrm{~ms}$ to the VTA via a World Precision Instruments PV830 pressure ejection device. To avoid glutamate toxicity, administration was limited to one puff every $2 \mathrm{~min}$. All pharmacological agents were dissolved in ACSF consisting of the following (in $\mathrm{mM}$ ): 5 $\mathrm{KCl}, 140 \mathrm{NaCl}, 1.4 \mathrm{CaCl}_{2}, 1.2 \mathrm{MgCl}_{2}$, and 5.0 glucose plus $\mathrm{KOH}$ to give a $\mathrm{pH}$ of 7.4. At the end of each experiment, rats were decapitated, and the brains were harvested and stored in $2 \%$ paraformaldehyde and $1 \%$ sucrose for histology.

In vivo intracellular recordings. Rats were anesthetized with a ketamine/xylazine mixture (20:6 mg/kg) and placed in a David Kopf Instruments (Tujunga, CA) stereotaxic device. The cisterna magna was drained, and a hole was drilled over the PFC (A/P, $3.2 \mathrm{~mm}$; lateral, \pm 0.6 $\mathrm{mm}$, ventral, $4-5.0 \mathrm{~mm} ; 10^{\circ}$ inclination) and the VTA $(\mathrm{A} / \mathrm{P},-4.9 \mathrm{~mm}$; lateral, $\pm 0.5 \mathrm{~mm}$; ventral, $7.7 \mathrm{~mm})$. Intracellular microelectrodes were pulled from Omegadot tubing (outer diameter, $1.5 \mathrm{~mm}$; World Precision Instruments, New Haven, CT) using a Narishige vertical puller (model PS2). The electrodes were filled with $3 \mathrm{~m}$ potassium acetate (electrode resistance, 25-40 M $\Omega$ in situ). Impalements were defined as stable if the resting membrane potential was at least $-55 \mathrm{mV}$ and the action potential amplitude was at least $50 \mathrm{mV}$. Signals were amplified by the NEURODATA IR-283 amplifier (Cygnus Technology, Delaware Water Gap, PA) filtered at $1 \mathrm{kHz}$ and connected via a National Instruments PCM-CIO $16 \mathrm{E} 4$ board to a personal computer running custom Labview software. Electrical stimulation of the VTA was delivered through bipolar concentric electrodes (model SNE-10; David Kopf Instruments). Single current pulses were delivered with a duration of $0.15 \mathrm{~ms}$ at a frequency of $2 \mathrm{~Hz}$ for EPSPs. For burst protocols, $120 \mu$ s monophasic pulses were delivered in $2 \mathrm{~s}$ bursts at $20 \mathrm{~Hz}$ (protocol 1), a pattern of eight bursts (five pulses, 100 $\mathrm{Hz}$ ) separated by $200 \mathrm{~ms}$ (protocol 2), or five bursts (four pulses, $500 \mathrm{~Hz}$ ) separated by $200 \mathrm{~ms}$ (protocol 3).

After successful impalement of a cell, at least $15 \mathrm{~min}$ of stable baseline recordings were obtained. Drugs were administered either intraperitoneally (1.5 mg/kg sulpiride) (Vives and Mogenson, 1986; Yanagihashi et al., 1991; Rosa-Kenig et al., 1993) or intravenously and used in the concentration range reported by others [AMPA/kainate antagonist 2,3dihydroxy-6-nitro-7-sulfonyl-benzo $(f)$ quinoxaline (NBQX), 12.5 $\mathrm{mg} / \mathrm{kg}$ (Li et al., 1999); NMDA antagonist (士)-3-(2-carboxypiperazin4-yl)propyl-1-phosphonic acid (CPP), $1 \mathrm{mg} / \mathrm{kg}$ (Hernandez et al., 1994; Connelly and Shepard, 1997); or SCH23390, $1 \mathrm{mg} / \mathrm{kg}$ (Lewis and O'Donnell, 2000; Brady and O'Donnell, 2004; Daniela et al., 2004)]. The delay between drug administration and VTA burst stimulation was 10 $\mathrm{min}$ for intraperitoneal injections and $3 \mathrm{~min}$ for intravenous injections. It should be noted that, although considered a selective $\mathrm{D}_{1}$ antagonist, SCH23390 also interacts with 5-HT receptors with an $\mathrm{IC}_{50}$ value of $30 \mathrm{~nm}$ in vitro and $1.5 \mathrm{mg} / \mathrm{kg}$ in vivo (Bischoff et al., 1986, 1988). The temperature of the animal was maintained at $36 \pm 0.5^{\circ} \mathrm{C}$ through a thermostatically controlled heating pad.

\section{In vivo voltammetry}

Separate groups of rats were used for voltammetric recordings. Rats were anesthetized with ketamine/xylazine and placed in a stereotaxic frame. Their temperature was maintained at $36.5^{\circ} \mathrm{C}$ with a thermostatically controlled heating pad (Harvard Instruments, Holliston, MA). The scalp was resected, and holes were drilled over the PFC (A/P, +3.2 mm; M/L, +0.6 $\mathrm{mm}$; skull flat) and the VTA (A/P, $-4.8 \mathrm{~mm} ; \mathrm{M} / \mathrm{L},+0.5 \mathrm{~mm}$; skull flat). A carbon-fiber microelectrode $(7 \mu \mathrm{m}$ diameter, $\sim 100 \mu \mathrm{m}$ exposed length, uncoated) was driven in a direction $10^{\circ}$ medial to vertical into the PFC to a depth of 3.5-5.0 mm beyond dura. Electrical stimulation of the VTA was delivered through bipolar concentric electrodes (model SNE10; David Kopf Instruments). The placement ranges for stimulating electrodes were -5.2 to $-6.3 \mathrm{~mm} \mathrm{~A} / \mathrm{P}, 0-1.2 \mathrm{~mm} \mathrm{M} / \mathrm{L}$, and -7.5 to $9 \mathrm{~mm}$ $\mathrm{D} / \mathrm{V}$ (VTA). DA release was evoked using $120 \mu$ s monophasic pulses delivered in $2 \mathrm{~s}$ bursts at $20 \mathrm{~Hz}$ (protocol 1), a pattern of eight bursts (five pulses, $100 \mathrm{~Hz}$ ) separated by $200 \mathrm{~ms}$ (protocol 2), or five bursts (four pulses, $500 \mathrm{~Hz}$ ) separated by $200 \mathrm{~ms}$ (protocol 3). DA was detected using fast-scan cyclic voltammetry at the carbon-fiber microelectrode. The electrode potential was held at $-0.4 \mathrm{~V}$ versus $\mathrm{Ag} / \mathrm{AgCl}$ and then, every 
$100 \mathrm{~ms}$, ramped to $+1.3 \mathrm{~V}$ and back at a scan rate of $400 \mathrm{~V} / \mathrm{s}$. Waveform application and data acquisition were accomplished with a computerbased system using custom software written in LabView. At each recording location (three to five per animal), each stimulation pattern was repeated five times at $5 \mathrm{~min}$ intervals, and the resultant signal was averaged.

DA was identified by its cyclic voltammogram (current-voltage relationship of its electrolytic reactions) (see Fig. 4). This provides a fairly unique signature for DA and allows it to be resolved chemically from most other biological electroactive species. However, norepinephrine produces a similar cyclic voltammogram to DA and is present at similar concentrations in the PFC. The selectivity of the measurements for DA over norepinephrine is gained by the specificity of the stimulation to evoke DA, because the stimulating electrode is stereotaxically implanted in the VTA where the DA cell bodies are located and signals are time locked to the stimulation (Garris et al., 1993)

\section{6-Hydroxydopamine lesions}

Animals were anesthetized with a mixture of ketamine/xylazyne (20:6 $\mathrm{mg} / \mathrm{kg}$ ) and fixed to a steretoaxic apparatus. The skin covering the skull was removed, and a hole was drilled over the VTA. A Hamilton syringe delivered $4 \mu \mathrm{l}(1 \mu \mathrm{l} / \mathrm{min})$ of 6-hydroxydopamine (6-OHDA) $(2.25 \mathrm{mg} /$ $\mathrm{ml})$. The needle was kept in place for an additional $5 \mathrm{~min}$ at the end of the injection. The animals were allowed to recover for 1 week and then were given injections of apomorphine $(0.05 \mathrm{mg} / \mathrm{kg})$ and tested for rotations for $1 \mathrm{~h}$. To consider an animal for electrophysiological recordings, the rats have to score at least 300 rotations/h.

\section{Immunohistochemistry}

Staining for tyrosine hydroxylase (TH) was achieved by standard peroxidase-antiperoxidase techniques. Sections were incubated at $4^{\circ} \mathrm{C}$ overnight in a primary antibody against $\mathrm{TH}$ from rabbit (Calbiochem, San Diego, CA) with $0.3 \%$ Triton X-100 (Fisher Scientific, Pittsburgh, PA) and $3 \%$ bovine serum albumin (Fisher Scientific). The following steps were performed at room temperature, separated by three washes in PBS for $10 \mathrm{~min}$ each. After washing, slices were first incubated for $1 \mathrm{~h}$ in biotinylated goat anti-rabbit (ABC Elite; Vector Laboratories, Burlingame, $\mathrm{CA}$ ) and then for $1 \mathrm{~h}$ in the avidin-biotin complex (1:100 in PBS with $0.3 \%$ Triton X-100; ABC Elite; Vector Laboratories). Staining was achieved by the VIP technique (three drops of reagents $1-3$ per $5 \mathrm{ml}$ of PBS; Vector Laboratories) and catalyzed by $\mathrm{H}_{2} \mathrm{O}_{2}$, yielding a violet signal. Next, stained sections were slide mounted with di- $n$-butylphthalate $x y$ lene and allowed to dry $24 \mathrm{~h}$ before visualization. Images that included the VTA region of both hemispheres were taken on a Nikon microscope (Optiphot-2) and digitized using Spot 6.1 (Diagnostic Instruments, Sterling Heights, MI). Scion Image (Scion, Frederick, MD) was used to quantify the density of TH-stained neurons in the slices. Values were assigned to each hemisphere by quantifying the VTA only. Each of these quantities representing a unilateral region of the VTA was then normalized to the deep mesencephalic nucleus to subtract background staining. The density of staining in nonlesioned and 6-OHDA-lesioned sections was compared. Recording and stimulation tracks and sites were confirmed using light microscopy in fixed slices.

\section{Data presentation and statistics}

One field or intracellular recording was obtained from a given animal (i.e., $n=1$ for each animal). For statistics, all responses for each cell during the baseline and all postdrug or poststimulation responses were collapsed, yielding two values for each cell. A paired cell $t$ test or ANOVA was used to compare differences between these values for a given experiment. For graphical presentations, each time point represented the average ( + SEM) response for all cells. To obtain a normalized baseline, an average was taken of all the responses from each individual cell before an experimental treatment. Each response at each time point for each cell was then divided by this individual cell average, multiplied by 100 , and subtracted by 100 to yield a percentage of change from the averaged baseline response of the individual cell.

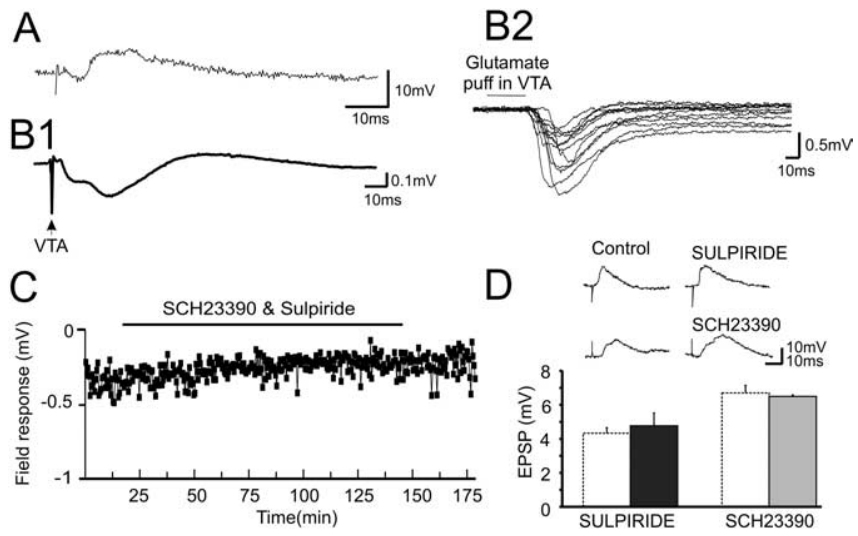

Figure 1. Properties of the response in the PFC to single-pulse electrical stimulation of the VTA. $\boldsymbol{A}$, Intracellular recordings from PFC neurons revealed an EPSP evoked by VTA stimulation. $B 1$, Averaged traces from 32 field recordings in the PFC elicited by VTA stimulation revealed a multiphasic waveform. B2, Representative field responses from 13 animals in which a glutamate pulse $(0.25-1 \mathrm{~mm}, 50 \mathrm{~ms})$ was delivered to the VTA. $C$, The $D_{1}$ and $D_{2}$ receptor antagonists $\mathrm{SCH} 23390(10 \mu \mathrm{m})$ and sulpiride $(10 \mu \mathrm{m})$ applied together to the PFC via reverse microdialysis did not modulate the field response significantly. D, Top, Representative traces in control and after sulpiride or $\mathrm{SCH} 23390$ application. Bottom, Group data showing that $D_{1}(\square ; 1 \mathrm{mg} / \mathrm{kg}$ $\mathrm{SCH} 23390 ; n=3$ ) or $\mathrm{D}_{2}$ (膡; $1.5 \mathrm{mg} / \mathrm{kg}$ sulpiride; $n=3$ ) antagonists did not affect the mean amplitude of the VTA-PFC EPSP relative to control $(\square)$ recorded intracellularly, suggesting that the response is not DA mediated.

\section{Results}

\section{Responses to single pulse VTA stimulation}

Single-pulse stimulation of the VTA evoked an EPSP in PFC neurons recorded intracellularly in vivo for cells held near -70 $\mathrm{mV}$ (Fig. 1A). Although the EPSP had a constant latency in a given neuron, there was variability in latencies across cells with an average onset of $13 \pm 5 \mathrm{~ms}$ (Fig. $1 \mathrm{~A}$ ). When held above $-60 \mathrm{mV}$, the EPSP was often followed by an IPSP that peaked at $23 \pm 4.3$ $\mathrm{ms}$ and lasted $\sim 50 \mathrm{~ms}$. This observation is consistent with previous observations in PFC neurons after VTA stimulation and striatal neurons after substantia nigra or MFB stimulation (Kitai et al., 1976; Kocsis and Kitai, 1977; Bernardi et al., 1982; Wilson et al., 1982; Mercuri et al., 1985; Lewis and O'Donnell, 2000).

Field potential recordings revealed additional components of the VTA-PFC response. The multiphasic field response consisted of two main components (Fig. 1B1). The first component showed a $4.68 \pm 0.45 \mathrm{~ms}$ latency to onset and $9.18 \pm 0.455 \mathrm{~ms}$ to peak with a mean amplitude of $-0.20 \pm 0.02 \mathrm{mV}(n=42)$. The second component had an onset latency of $15 \pm 1.39 \mathrm{~ms}$ and a peak of $-1.69 \pm 0.6 \mathrm{mV}$ at $21 \pm 3.25 \mathrm{~ms}$, which was in reasonable agreement with the intracellular EPSP. In $42 \%$ of fields, a later positive-going component was also present with an onset latency of $43.3 \pm 2.7 \mathrm{~ms}$ and peak of $0.29 \pm 0.026 \mathrm{mV}$. The first and second negative-going components reflect the presynaptic volley and postsynaptic components of the orthodromic response, respectively, whereas the last positive-going component likely represents a field IPSP. This interpretation of the field response is consistent with the interpretation of field responses observed in other cortical or hippocampal regions (Andersen et al., 1978; Kimura et al., 1989; Bear et al., 1992; Varela et al., 1997; Chapman et al., 1998). Despite the presence of a descending PFC-VTA pathway in the rat (Beckstead, 1979), we only observed a fast population spike (antidromic spike) preceding the first component of the field response in a minority of recordings (14 of 42; $33.3 \%)$.

Glutamate injections into the VTA should activate only VTA neurons and should not stimulate axons that pass through the 
VTA or axons descending from the PFC. As shown in Figure 1B2, when glutamate (0.25-1 mM) was applied locally into the VTA by pressure ejections ( $50 \mathrm{~ms}$ ), a large amplitude field response was observed in the PFC. On some trials, a single peak was observed representing the postsynaptic response, whereas on other trials, a dual peak like that illustrated in Figure $1 C$ was present, showing in addition, the presynaptic volley.

\section{Pharmacology of the PSP induced by VTA stimulation}

To test which neurotransmitter system is responsible for the PSP evoked by VTA stimulation, pharmacological blockers of DA and glutamate receptors were applied either systemically or locally into the PFC through reverse dialysis. $D_{1}$ and $D_{2}$ antagonists were given alone or in combination. The field response showed no significant change in amplitude during the period of reverse dialysis of both antagonists [reverse dialysis, $n=6$ (Fig. $1 C$ ); systemic, $n=3$ (data not shown)]. Likewise, systemic injection of a $\mathrm{D}_{1}$ antagonist or a $\mathrm{D}_{2}$ antagonist also did not reduce the amplitude of the VTA-induced EPSP recorded intracellularly in vivo $(n=6)$ (Fig. $1 D)$. These data suggest the PSP that resulted from VTA stimulation was not mediated by DA receptors.

We repeated these experiments using glutamate receptor antagonists. Reverse dialysis of the non-NMDA antagonist CNQX $(10 \mu \mathrm{M})$ produced a large reduction in the second component of the field response evoked by VTA stimulation (control amplitude, $0.6 \pm 0.02 \mathrm{mV}$; amplitude in the presence of CNQX, $0.03 \pm 0.004 \mathrm{mV} ; n=6 ; p<0.01$ ) (Fig. 2A,B), suggesting that this component, which represents the postsynaptic response, was glutamate mediated. Note that the first negative peak of the multiphasic response was still present after CNQX administration (Fig. $2 A, B$, open squares), because this peak represents the presynaptic component of the response.

Similar experiments were conducted using intracellular recordings. Systemic injection of NBQX $(12.5 \mathrm{mg} / \mathrm{kg})$ and CPP (1 $\mathrm{mg} / \mathrm{kg}$ ) completely eliminated the EPSP in all neurons tested (control amplitude, $4.4 \pm 2.3 \mathrm{mV}$; amplitude in glutamate antagonists, $0.23 \pm 0.72 ; n=8 ; p<0.01$ ) (Fig. $2 C$ ). In cells in which an IPSP was present under baseline conditions, it was also eliminated by non-NMDA antagonists. Reverse dialysis of the GABA antagonist bicuculline $(10 \mu \mathrm{M})$ produced a large increase in the second component of the field response (Fig. $2 D, E$ ), highlighting the importance of GABAergic currents. However, it is important to emphasize that both in the present study and in our previous study (Seamans et al., 2003), blockade of glutamate receptors usually eliminated the electrophysiological response to VTA stimulation. Glutamatergic antagonists delivered to the PFC should not block an IPSP produced by GABAergic efferents from the VTA to the PFC (Carr and Sesack, 2000). Rather, because both the EPSP and IPSP were eliminated by CNQX or NBQX, it suggests that the IPSP is mediated by VTA-induced feedforward activation of local PFC interneurons. Activation of these interneurons then produces the IPSP recorded in the field or intracellularly in PFC pyramidal cells. Together, these data suggest that the PSP evoked by VTA stimulation is initiated by glutamatergic and not DAergic receptors in the PFC.

\section{The potential influence of fibers of passage and antidromic fiber activation}

Although stimulation of DA neurons consistently has been reported to induce PSPs in target regions, one cannot be certain that such stimulation exclusively activates ascending DA fibers (Wilson et al., 1982). For instance, the PSP may be produced by activation of fibers of passage. Alternatively, VTA stimulation may depolarize the axon terminals of descending PFC-VTA fibers and cause an antidromic action potential to travel back to the PFC. Axon collaterals of these activated fibers may then excite neighboring deep-layer PFC neurons to produce the observed PSP. Although such responses could not be produced by glutamate injections into the VTA (Fig. 1B2), we conducted a series of additional experiments to further test these possibilities.

Unlike the ascending DA fibers that travel to the PFC through the MFB, the descending pathway from the PFC to the VTA travels mainly through the internal capsule/cerebral peduncle 

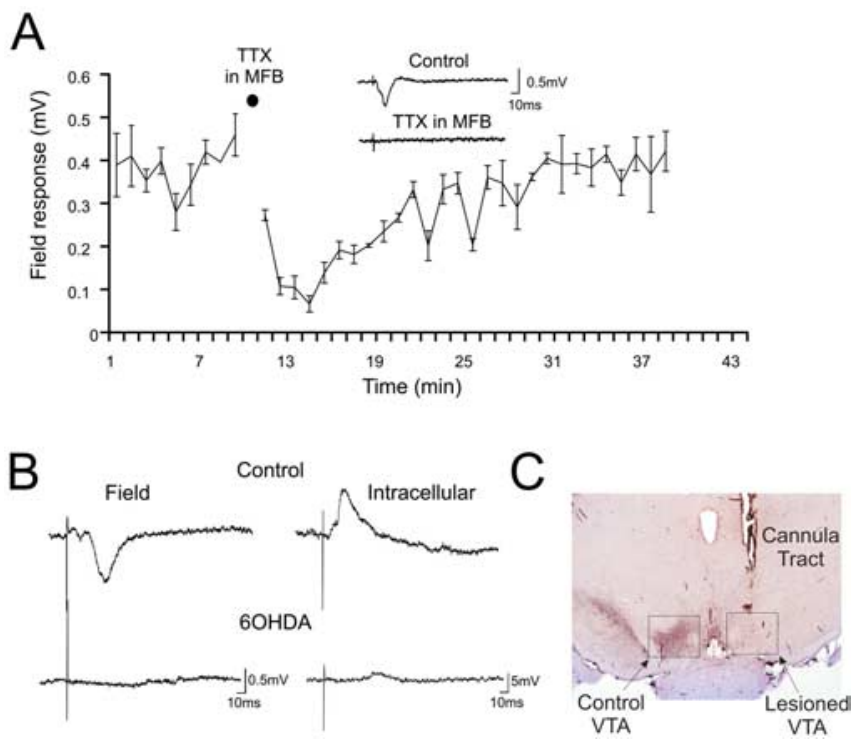

Figure 3. Response in the PFC to VTA stimulation is blocked by MFB inactivation or 6-OHDA VTA lesions. A, A concentration of $1 \mu \mathrm{m}$ TTX puffed to the MFB abolishes the averaged evoked amplitude of the postsynaptic component of the field response $(n=8)$. Inset, Representative trace of the field response before and after the TTX puff into the MFB. The stimulus artifact was cropped for clarity. $\boldsymbol{B}$, Left, Field response in the PFC evoked by VTA stimulation in a control rat (top) and in a rat with a 6-OHDA lesion of the VTA (bottom). Right, Intracellular recording of a PFC neuron after VTA stimulation in a control rat (top) and from a rat with a 6-OHDA lesion of the VTA (bottom). C, Photomicrograph of a representative section through the VTA stained for TH.

(Beckstead, 1979). Therefore, if the response in the PFC was an artifact of antidromic activation of descending PFC-VTA fibers, blocking activity in the MFB should be without effect. This hypothesis was tested by focally pressure ejecting $1 \mu \mathrm{M}$ TTX into the part of the MFB (A/P, +0.2; M/L, 1.8; D/L, 8.8) that is the most spatially separated from the descending pathway. As shown in Figure 3A, TTX application into the MFB almost completely eliminated the field PSP produced by electrical stimulation of the VTA $(p<0.01 ; n=8)$, suggesting that the field responses shown in Figure 1 are attributable mainly to ascending VTA-PFC fibers and not to antidromic activation of descending PFC-VTA fibers.

The experiments described above did not specifically address the question of whether it was actually DA cells and not some other cell type in the VTA that produced the PSP in the PFC. To test the specific contribution of DA cells, 6-OHDA was injected unilaterally into the VTA to lesion DA cells in one hemisphere. Stimulation of the 6-OHDA-lesioned VTA failed to evoke a PSP in the ipsilateral PFC recorded either extracellularly or intracellularly, even when higher stimulation intensities than normally required were delivered (Fig. $3 B$ ). The fact that a PSP was observed in control animals and not in adequately lesioned animals suggests that DA neurons are needed to generate the response. It is also important to emphasize the lack of an IPSP in the PFC after VTA 6-OHDA lesions. This finding supports the conclusion stated above: that the IPSP was as a result of feedforward drive from the VTA onto PFC interneurons rather than the GABAergic VTA-PFC pathway, which should have been relatively spared by 6-OHDA lesions.

The histological representation of a 6-OHDA lesion is shown in Figure 3C. Densitometry showed that the 6-OHDA-lesioned animals had significantly less staining for TH $(18.19 \pm 1.77)$ than nonlesioned animals $(36.14 \pm 4.17)$ measured in arbitrary optical units with background subtracted $(n=5$; $p<0.01)$. Thus, although the PSP is not produced by DA receptors in the PFC,

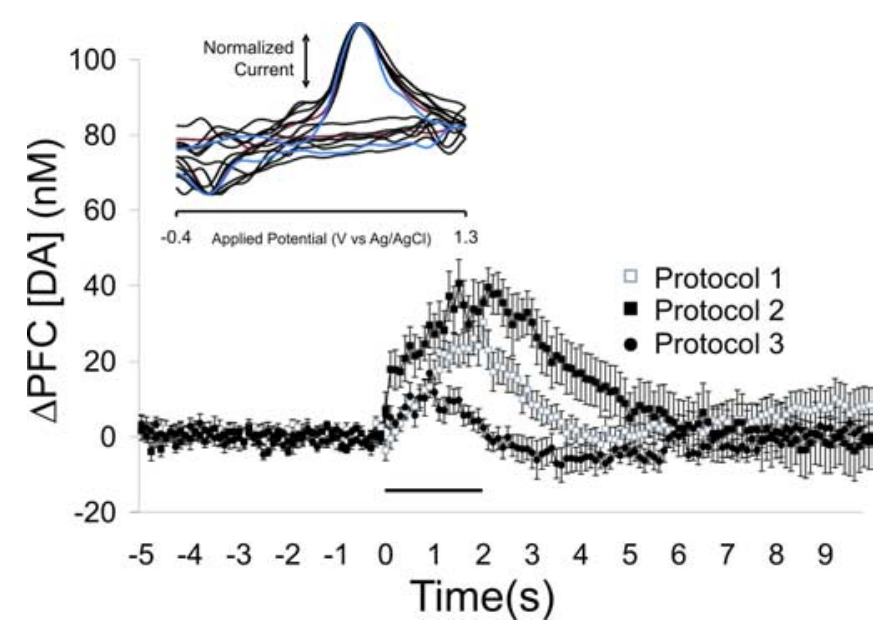

Figure 4. Burst stimulation of the VTA evokes transient increases in PFC [DA]. Stimulation of the VTA using protocol $1(20 \mathrm{~Hz} / 2 \mathrm{~s})$, protocol 2 (8 bursts, 5 pulses at $100 \mathrm{~Hz}$ separated by 200 $\mathrm{ms})$, and protocol 3 ( 5 bursts, 4 pulses at $500 \mathrm{~Hz}$ separated by $200 \mathrm{~ms}$ ) evoked an increase in PFC $[D A]$ as measured with a carbon-fiber probe in vivo using fast-scan voltammetry (average + SEM from 3 rats per protocol) that returned to basal levels within seconds. The horizontal line represents the stimulation period. Inset, Normalized cyclic voltammograms from six separate recording sites in the PFC (black lines) showing that the detected signal is very similar $\left(r^{2}=\right.$ $0.91-0.98)$ to that for authentic DA in vitro (1 $\mu \mathrm{m}$; red line). The blue line is a cyclic voltammogram for released DA in the nucleus accumbens core after stimulation of the VTA ( 4 pulses, 20 $\mathrm{Hz}$ ), shown for comparison $\left(r^{2}=0.95\right.$ vs authentic DA).

VTA-PFC signaling appears to be transmitted by DA axons. Furthermore, 6-OHDA should not destroy fibers of passage or antidromic PFC-VTA fibers, yet no PSP was observed in lesioned animals.

\section{Effects of phasic VTA activation on PFC DA levels}

Garris et al. (1993) showed previously that short bursts of stimulation to the VTA effectively caused phasic DA release in the PFC in the nanomolar range. In the present study, three burst patterns were chosen based on the firing properties of VTA neurons recorded extracellularly in behaving animals (Freeman et al., 1985; Freeman and Bunney, 1987; Kiyatkin, 1988). Rat VTA DA cells fire in $15-20 \mathrm{~Hz}$ bursts of $<2 \mathrm{~s}$ in duration. Accordingly, we used a stimulation pattern of $20 \mathrm{~Hz} / 2 \mathrm{~s}$ (protocol 1) to mimic this activity. Faster bursts are also sometimes observed consisting of three to six spikes at $67-200 \mathrm{~Hz}$. Therefore, an additional burst protocol was used to mimic this pattern [eight trains of five pulses at $100 \mathrm{~Hz}$ separated by $200 \mathrm{~ms}$ (protocol 2)]. A third protocol was also used that had fewer pulses but at a much higher frequency than normally observed in VTA neurons [five trains of four pulses at $500 \mathrm{~Hz}$ separated by $200 \mathrm{~ms}$ (protocol 3)].

A total of six rats were used for electrochemical recordings. Each stimulation protocol was run at 3-5 recording sites per rat, amounting to 12 recording sites for protocol 1, 9 recording sites for protocol 2, and 10 recording sites for protocol 3. At any recording site, data were collected for each stimulation protocol. Each protocol was applied five times at $5 \mathrm{~min}$ intervals. The resulting electrochemical data from the five replicates were averaged and considered as a single data point. Therefore, the error bars on the graphs represent the variance between recording sites within the PFC and do not account for the small amount of variance between replicates within a site. As shown in Figure 4, protocol 1 evoked a maximum release of DA of $30.6 \mathrm{nM}(n=12$ recording sites), whereas protocol 2 evoked a maximum release of $40.6 \mathrm{nM}$ ( $n=9$ recording sites) that decayed back to baseline within $2 \mathrm{~s}$ after the burst. Protocol 3 evoked a smaller increase in 
PFC DA levels that peaked at $16.9 \mathrm{~nm}$ and also decayed back to baseline within $2 \mathrm{~s}$ of the end of the stimulation ( $n=10$ recording sites). Therefore, these stimulation patterns effectively increase PFC DA levels for a brief period of time.

\section{Effects of transient VTA activation on PFC firing}

As noted above, VTA stimulation reduces spontaneous firing of PFC neurons measured extracellularly in vivo, whereas DA increases firing in response to intracellular current injection in vitro. Using intracellular in vivo recordings, it is possible to measure both spontaneous and current-pulse evoked firing in vivo. For these experiments, identical stimulating electrodes and stimulation protocols were used as for voltammetry experiments shown in Figure 4. As described previously (Lewis and O'Donnell, 2000; Seamans et al., 2003), burst stimulation of the VTA could sometimes evoke up states in the PFC ( $n=8$ of 62) (Fig. 5A). At present, it is unclear how VTA-induced up states compare with rhythmic spontaneous up states also observed in the cortex in vivo.

In the present study, firing was always analyzed in the period beginning $30 \mathrm{~s}$ after VTA stimulation, well after the up state had terminated. After VTA stimulation, a reduction in firing frequency was observed for neurons that fired spontaneously but did not exhibit spontaneous up/downstate transitions $(n=7 ; p<0.05)$ (Fig. $5 B, C)$. Such cells fired spontaneously but were not bistable and had an overall unimodal membrane potential distribution. In contrast, the same burst stimulation of the VTA had no effect on firing of bistable neurons during spontaneous up-state periods $(n=13)$ (Fig. $5 D)$. This differential effect likely reflects the fact that spontaneous firing from rest is initiated mainly by spontaneous AMPA-like EPSPs that are reduced by DA (Seamans et al., 2001a), whereas up states are mediated by a balanced mix of $\mathrm{GABA}_{\mathrm{A}}$ and NMDA currents that are enhanced equivalently by $\mathrm{DA}$ (Durstewitz et al., 2000; Seamans et al., 2001a,b; Seamans et al., 2003; Shu et al., 2003; Seamans and Yang, 2004).

In vitro, DA strongly enhances firing to a depolarizing input, such as an intracellular current pulse (Yang and Seamans, 1996; Gorelova and Yang, 2000; Henze et al., 2000; Gulledge and Jaffe, 2001). In the present study, a large progressive increase in this type of evoked excitability was observed after VTA burst stimulation using protocol 1 or 2 (protocol 1: $n=14, p<0.004$; protocol 2: $n=5, p<0.05$ ) (Fig. $5 E-G)$. In contrast, the third "nonphysiological" stimulation protocol not only evoked less PFC DA release, it also had a nonsignificant effect on evoked firing (baseline firing per bin, $5.5 \pm$ and protocol 2 (G).
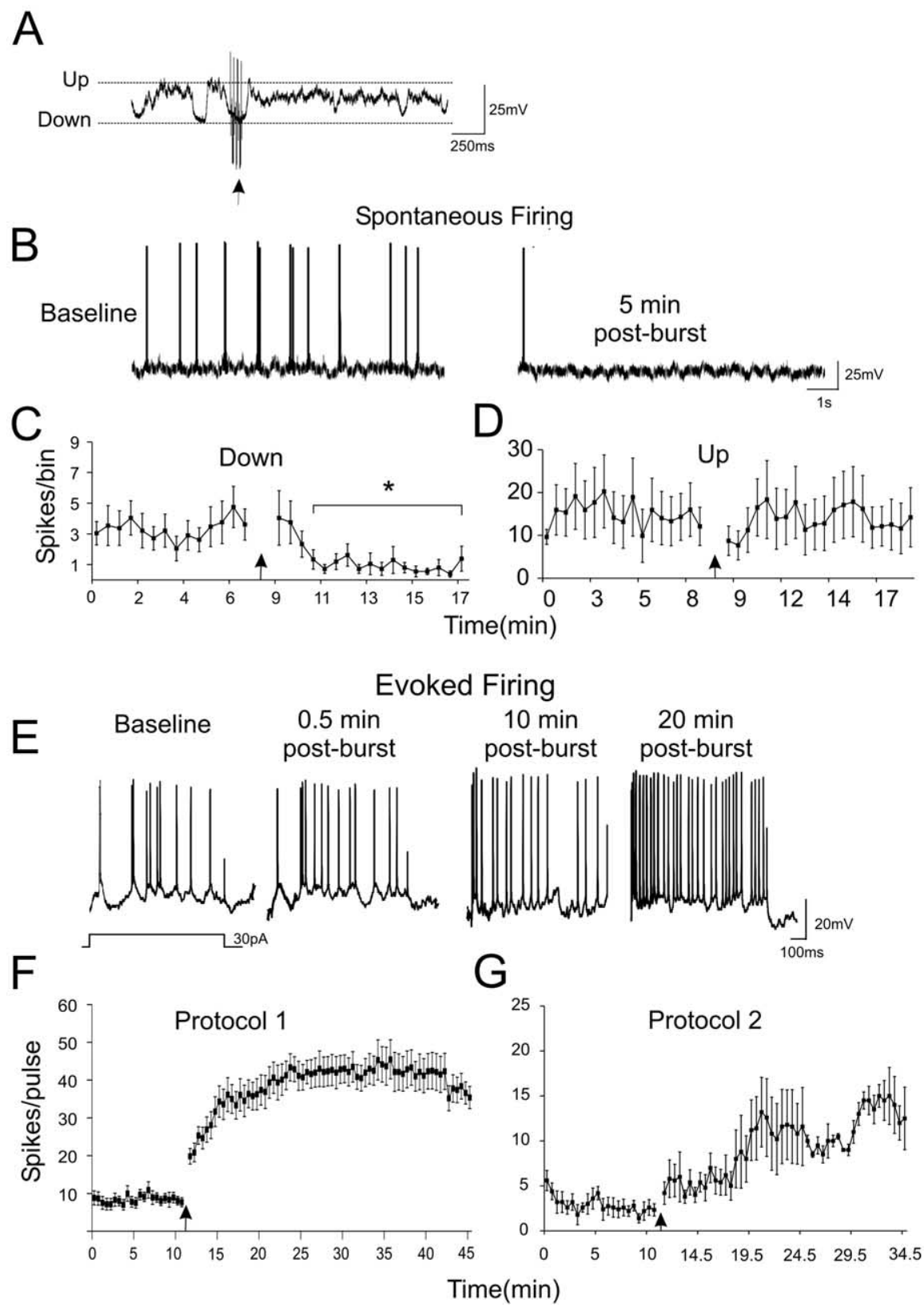

Figure 5. Phasic VTA stimulation differentially modulates spontaneous and evoked firing of PFC neurons for prolonged periods. $\boldsymbol{A}$, Burst stimulation of the VTA could induce up states in the PFC. The arrow indicates the time of the $20 \mathrm{~Hz}$ burst. $\boldsymbol{B}$, Representative intracellular traces from a PFC neuron that did not exhibit spontaneous up/down-state transitions. The neuron fired spontaneously during the baseline recording period (left), but this firing was reduced $5 \mathrm{~min}$ after VTA stimulation (right). C, Group data showing the mean (+SEM) change in spontaneous firing after burst stimulation of the VTA for PFC neurons that exhibited no up/down-state transitions but fired spontaneously. $D$, Group data showing the mean (+SEM) change in spontaneous firing after burst stimulation of the VTA for PFC neurons that exhibited clear up/down-state transitions and fired during the up state. $\boldsymbol{E}$, Representative traces of a PFC neuron recorded intracellularly in vivo that fired in response to intracellular depolarizing current pulses, during the baseline recording period and $0.5,10$, and 20 min after VTA stimulation. $\boldsymbol{F}, \mathbf{G}$, Group data of the mean $(+$ SEM) change in intracellular current-pulse-evoked firing of PFC neurons after burst stimulation of the VTA using protocol $1(\boldsymbol{F})$

0.3 ; after stimulation, $8.3 \pm 2 ; p=0.2 ; n=4$; data not shown). Thus, a minimum DA concentration ([DA]) appears to be required to produce the increase in evoked firing. Yet, there does not appear to be a linear relationship between [DA] and firing modulation, because protocol 2 produced a greater increase in DA than protocol 1 , yet had less of an effect on spiking. During all experiments, the membrane potential was monitored closely, and changes in $V_{\mathrm{m}}$ were corrected by the addition of current via 

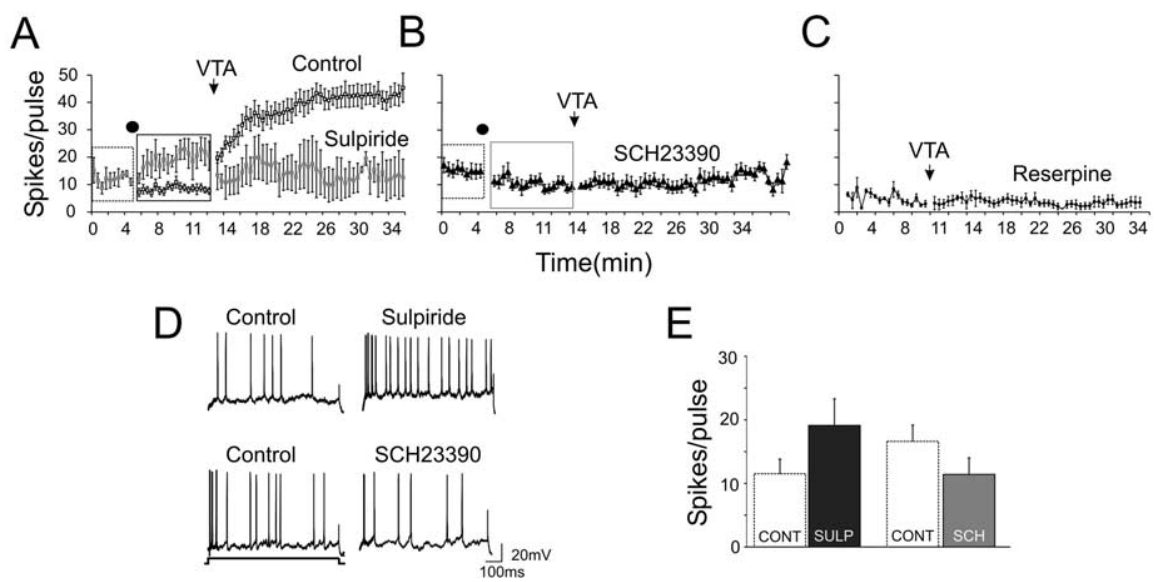

Figure 6. The VTA burst-induced increase in evoked firing is blocked by manipulation of the DA system. $\boldsymbol{A}-\boldsymbol{C}$, Group data showing the mean ( + SEM) change in intracellular current-pulse-evoked firing of PFC neurons after burst stimulation of the VTA in the control condition $(\square)$, in the presence of $D_{2}$ antagonist sulpiride $(\boldsymbol{A})$, in the presence of $D_{1}$ antagonist $S C H 23390(\boldsymbol{B})$, or in reserpine-treated rats $(\boldsymbol{C})$. The black dot indicates when drugs were delivered. The arrow indicates the time of electrical stimulation delivered into the VTA. D, Representative traces showing the effects of sulpiride alone (top) and SCH23390 (bottom) on evoked firing. $\boldsymbol{E}$, Collapsed data replotted from the boxed regions in $\boldsymbol{A}$ and $\boldsymbol{B}$. Control (CONT; $\square$ ) data were from the dashed boxes in $\boldsymbol{A}$ and $\boldsymbol{B}$, whereas sulpiride data were taken from the black box in $\boldsymbol{A}$ and $\mathrm{SCH} 23390$ data were taken from the gray box in $\boldsymbol{B}$. Before any VTA stimulation, sulpiride (SULP; $\square$ ) produced an increase in evoked firing, whereas SCH23390 (SCH; 畻) reduced evoked firing relative to baseline firing.

the recording electrode. Collectively, the data suggest that for some period after a significant phasic DA release event, both a reduction in spontaneous firing in the down state and a prolonged increase in depolarization-induced firing are seen.

\section{Effect of DA antagonists on tonic excitability and VTA burst-induced potentiation}

In the absence of VTA stimulation, there is a background level of DA in the PFC that is in the nanomolar range as measured with microdialysis (Hedou et al., 2001; Marsteller et al., 2002; Phillips et al., 2004). This tonic background level of DA modulated the intrinsic excitability of PFC neurons. After the baseline period, either a $\mathrm{D}_{1}$ antagonist or $\mathrm{D}_{2}$ antagonist was delivered in separate experiments. In the absence of VTA stimulation, the $\mathrm{D}_{2}$ antagonist alone increased the average evoked excitability measured in the $5-10 \mathrm{~min}$ after injection by $42.8 \pm 20 \%(p<0.03 ; n=6)$ (Fig. $6 \mathrm{~A}$ ). In contrast to a $\mathrm{D}_{2}$ antagonist, the $\mathrm{D}_{1}$ antagonist decreased the average evoked excitability by $-24.6 \pm 6.7 \%(p<$ $0.04 ; n=7$ ) (Fig. 6B). These effects in PFC neurons replicated previous findings from striatal neurons (West and Grace, 2002) and demonstrate that tonic DA acts in an opposing manner via $D_{1}$ and $D_{2}$ receptors to regulate excitability.

Shortly after the administration of DA antagonists, $20 \mathrm{~Hz} / 2 \mathrm{~s}$ (protocol 1) stimulation of the VTA was applied. In both groups of animals receiving either the $\mathrm{D}_{1}$ or $\mathrm{D}_{2}$ antagonist, the increase in evoked excitability was no longer observed (Fig. $6 A, B$ ). In Figure $6 A$, data previously presented in Figure 5 was replotted (open squares) to highlight the effect of VTA stimulation in the absence of DA antagonists. These data show that both $\mathrm{D}_{1}$ and $\mathrm{D}_{2}$ receptors are required for the expression of the VTA-induced increase in evoked excitability.

As additional evidence that the prolonged effects were a direct result of DA released by VTA stimulation, a group of animals were given reserpine injections $(2.5 \mathrm{mg} / \mathrm{kg}) 12-24 \mathrm{~h}$ before recordings. This treatment significantly depletes PFC DA (Bean et al., 1989). Protocol 1 stimulation of the VTA produced no increase in the evoked excitability of PFC neurons in reserpine- treated rats (Fig. $5 C$, filled circles), indicating that DA released by VTA stimulation was responsible for the increase in evoked excitability (Fig. 6C, open squares).

\section{Discussion}

The results of the present study show that electrical or chemical stimulation of the VTA can evoke a short-latency PSP in the PFC that lasts tens of milliseconds and is blocked by 6-OHDA lesions of the VTA, transient lesions of the MFB, or administration of glutamatergic receptor antagonists but not of DA receptor antagonists. Phasic burst stimulation of the VTA evokes transient rises in the PFC [DA] that peak at 30-40 nM and decay to baseline levels in $<2$ s. This stimulation reduced spontaneous firing but enhanced evoked firing for a period that far outlasted the period of elevated DA levels. This effect was blocked by DA antagonists or catecholamine depletion. These results suggest that the $\mathrm{PFC}$ receives a fast non-DA-mediated signal from the VTA and a slower DA-mediated signal that differentially affects spontaneous and depolarization-evoked firing for prolonged periods.

\section{Issues related to the fast signal emanating from the VTA}

There is emerging physiological evidence for corelease of glutamate from DA neurons. TH-positive neurons are immunoreactive for glutamate in primate and rat slices, and DA neurons grown in primary cultures make glutamatergic synapses that can produce both autaptic glutamatergic EPSPs or EPSPs in neighboring cells (Sulzer et al., 1998; Joyce and Rayport, 2000). Yet, one might argue that glutamate immunoreactivity does not mean that glutamate is actively being released as a neurotransmitter, given the ubiquity of glutamate in neurons. It is also possible that neurons grown in primary culture may lose their DA phenotype and become glutamatergic although they still are TH immunopositive. However, Chuhma et al. (2004) have shown that stimulation of yellow fluorescent protein-labeled TH neurons from the VTA produced a glutamatergic EPSC in an acute brain slice preparation that preserved the meso-accumbal pathway. This important observation lends credence to the idea of glutamate corelease in DA neurons.

Yet, there are important issues relating to glutamate corelease from DA neurons that remain unresolved. First, there is currently very little evidence that a substantial portion of DA axons make asymmetric synapses, characteristic for glutamate (Descarries et al., 1987; Ikemoto et al., 1996; Hanley and Bolam, 1997). Second, although VTA neurons in primary culture are immunopositive for the vesicular glutamate transporter VGluT2 (Dal Bo et al., 2004), VTA neurons in fresh tissue have not yet been shown to express this protein or mRNA (Bellocchio et al., 1998; Fujiyama et al., 2001; Dal Bo et al., 2004). In contrast, although VGluT3 has been found at symmetrical as well as asymmetrical synapses and VGluT3 expression is present in neurons containing vesicular acetylcholine transporter, vesicular monoamine transporter, tryptophan, and GAD, evidence for colocalization of $\mathrm{TH}$ and VGluT3 has proven elusive (Fremeau et al., 2002; Grass et al., 2002; Schafer et al., 2002; Herzog et al., 2004). Thus, although 
clear anatomical and molecular evidence for corelease of glutamate from DA neurons is pending, the accumulation of recent physiological data and the evidence of corelease in other classical "neuromodulatory" systems (Johnson, 1994; Johnson and Yee, 1995; Fremeau et al., 2002; Grass et al., 2002; Schafer et al., 2002; Herzog et al., 2004) strongly suggests that DA neurons are indeed capable of glutamate corelease.

\section{Comparison with previous in vivo studies}

A long history of studies has shown that DA exerts an "inhibitory" effect on the excitability of pyramidal cells recorded extracellulary in vivo. Specifically, VTA stimulation suppresses spontaneous spike firing for a period of $\sim 200 \mathrm{~ms}$ (Bunney and Aghajanian, 1976; Sesack and Bunney, 1989; Godbout et al., 1991; Pirot et al., 1992). In the present study, an IPSP was observed in the field and intracellular recordings, and a GABA antagonist greatly increased the amplitude of the excitatory component of the field response. Thus, as suggested previously (Pirot et al., 1992), much of the inhibition of spontaneous PFC firing after VTA stimulation may actually be the result of the GABAergic component of the multiphasic response. In contrast, in the present study, a reduction in spontaneous firing from rest was observed after the fast PSP terminated. This effect was quite potent in suppressing PFC firing, reminiscent of the effects reported in the studies cited above. Therefore, it is likely that both the IPSP component of the mixed PSP and the cessation in spontaneous firing shown in Figure 5 were responsible for the classical actions of VTA stimulation recorded extracellularly in vivo.

\section{DA dynamics in PFC}

The long-lasting effects of VTA stimulation may be attributable to lingering DA levels or phasic activation of DA receptors that then have prolonged actions via intracellular signaling cascades. Although data presented in Figure 4 suggest that DA levels return to baseline in seconds, this technique is not optimal for assessing tonic changes in $[\mathrm{DA}]$. Insight into this question may, however, be garnered from considerations of DA dynamics in the PFC. The average diameter of a DA synapse in the PFC is $200 \mathrm{~nm}$ (Seguela et al., 1988), giving it an extracellular volume of $\sim 6 \times 10^{-22} \mathrm{~m}^{3}$ (assuming the geometry is a 20 -nm-thick disk). Within $10 \mu$ s of exocytosis, the 10,000-30,000 DA molecules released (Hochstetler et al., 2000; Staal et al., 2004) will have diffused throughout the synapse (diffusion coefficient $\left.=6.9 \times 10^{-6} \mathrm{~cm}^{2} / \mathrm{s}\right)($ Gerhardt et al., 1996) to give a synaptic concentration of $\sim 30-100 \mathrm{~mm}$. Because DA varicosities are fairly sparse in the PFC $\left(10^{6}\right.$ per cubic meter) (Descarries et al., 1987), this concentration is rapidly depleted, by radial diffusion (Cragg and Rice, 2004), to nanomolar levels in the extrasynaptic compartment. However, DA can diffuse relatively large distances in the PFC because there are few DATs (Sesack et al., 1998) and, consequently, slow uptake (Garris et al., 1993, 1994), which may result in a rather steady-state and spatially homogeneous concentration. Because $\mathrm{D}_{1}$ receptors are often, if not exclusively, located extrasynaptically (Smiley et al., 1994; Yung et al., 1995; Caille et al., 1996), they are not likely to see the high localized and transient intrasynaptic DA levels. From the perspective of $D_{1}$ receptors, phasic DA release may only serve to increase overall extrasynaptic DA levels in the PFC. In contrast, $\mathrm{D}_{2}$ receptors, if located closer to a release site or synapse, may detect and respond more quickly to these transient rises in DA.

\section{A theory of mesocortical signaling}

Midbrain DA neurons respond by firing a $\sim 200 \mathrm{~ms}$ burst of spikes to primary rewards, conditioned or secondary rewards
(Hyland et al., 2002), rewards that are not predicted (Hollerman and Schultz, 1998), and novel or unexpected stimuli (Miller et al., 1981; Rasmussen et al., 1986; Freeman and Bunney, 1987; Schultz 1997, 1998). Such response properties suggest that DA neurons respond to "salience" (Le Moal and Simon, 1991; Schultz, 1997; Hyland et al., 2002). According to Schultz (1997, 1998), DA neurons are activated by rewarding events that are better than predicted, remain unaffected by events that are as good as predicted, and are depressed by events that are worse than predicted. In this way, the firing of DA neurons may generate "a prediction error" about rewards.

DA neurons also exhibit a significant and tonic elevation in firing from sleep to active wakefulness (Steinfels et al., 1983), which is more compatible with the idea that DA neurons exert a "state-dependent function" perhaps providing a "tonicactivational influence" (Strecker et al., 1983) on target regions. Measurement of DA neurotransmission in the PFC is also compatible with such a state-dependent function. In response to behavioral stimuli, extrasynaptic DA levels typically rise slowly to a plateau level and, after reaching this plateau, slowly return to baseline. Light handling, novelty, or delivery of food to a hungry rat potently increases DA levels in the PFC for tens of minutes (Feenstra et al., 1995, 2000; Feenstra and Botterblom, 1996; Taber and Fibiger, 1997; Watanabe et al., 1997; Ahn and Phillips, 1999). Furthermore, negative events such as stress (Finlay et al., 1995; Yoshioka et al., 1996; Finlay and Zigmond, 1997; Del Arco and Mora, 2000) also increase PFC DA levels for prolonged periods.

Yet, these in vivo microdialysis DA measurements have poor temporal resolution and cannot detect fast synaptic DA fluctuations on a millisecond time scale that is possible with voltammetric measurements (Phillips et al., 2003). In contrast, extrasynaptic DA measured with microdialysis may actually reflect functional PFC DA levels because of the known diffusional action of DA, especially at $D_{1}$ receptors that are extrasynaptic as noted above. As a result, it is difficult to envision how extrasynaptic $D_{1}$ receptors could "sense" the difference between large lingering levels of extrasynaptic DA produced by a previously encountered salient stimulus some minutes ago, versus a more recently encountered stimulus. Data shown in Figures 5 and 6 suggest that these receptors are not well suited to translate a transient release of DA into a transient electrophysiological response.

Our data provide a means to reconcile these various hypotheses of DA function. The firing of VTA neurons could encode salience or a prediction error signal in accordance with singleunit recording data (Schultz, 1997, 1998), yet this signal may be transmitted via glutamate coreleased from VTA terminals in the $\mathrm{PFC}$, rather than by DA. In this scenario, glutamate that is coreleased actually transmits the temporally precise information. This hypothesis frees DA from the burden of encoding both fast and slow signals and partly transfers it to the glutamate system that is exquisitely suited to produce transient changes in neural activity.

It is thought that PFC networks retain information in working memory via persistent activity patterns (Goldman-Rakic, 1995). The VTA can evoke persistent activity states in the PFC that are dependent on glutamate rather than DA receptors (Lewis and O'Donnell, 2000; Seamans and Yang, 2004). Therefore, the firing of VTA neurons in response to reward may release glutamate in the PFC, which can evoke a persistent activity state in the PFC that signals that an event is "better than predicted" and to hold this information in working memory. In contrast, DA exerts prolonged changes in ionic currents in vitro, and computational models suggest that these changes alter network dynamics to re- 
strict or enhance access to PFC networks, while greatly strengthening currently maintained representations in working memory (Compte et al., 2000; Durstewitz et al., 2000; Durstewitz and Seamans, 2002). In this scheme, DA provides no specific information but rather biases how PFC networks will respond to afferents that evoke persistent activity states. Several glutamateevoked persistent activity states may occur within a short period of time, yet these states would be processed differently depending on the already established DA tone. Thus, when an animal enters an environment rich with unexpected rewards, DA transmission may maintain a state of cognitive attention, lasting many minutes. Numerous glutamatergic inputs are capable of activating working memory networks in the PFC, but the VTA may be unique in that it provides both transient reward-related information as well as exerting state-dependent control of PFC networks via release of DA.

\section{References}

Ahn S, Phillips AG (1999) Dopaminergic correlates of sensory-specific satiety in the medial prefrontal cortex and nucleus accumbens of the rat. J Neurosci 19:RC29(1-6).

Andersen P, Silfvenius H, Sundberg SH, Sveen O, Wigstrom H (1978) Functional characteristics of unmyelinated fibers in the hippocampal cortex. Brain Res 144:11-18.

Bean AJ, Adrian TE, Modlin IM, Roth RH (1989) Dopamine and neurotensin storage in colocalized and noncolocalized neuronal populations. J Pharmacol Exp Ther 249:681-687.

Bear MF, Press WA, Connors BW (1992) Long-term potentiation in slices of kitten visual cortex and the effects of NMDA receptor blockade. J Neuropshysiol 67:841-851.

Beckstead RM (1979) An autoradiographic examination of corticocortical and subcortical projections of the mediodorsal-projection (prefrontal) cortex in the rat. J Comp Neurol 184:43-62.

Bellocchio EE, Hu H, Pohorille A, Chan J, Pickel VM, Edwards RH (1998) The localization of the brain-specific inorganic phosphate transporter suggests a specific presynaptic role in glutamatergic transmission. J Neurosci 18:8648-8659.

Bernardi G, Cherubini E, Marciani MG, Mercuri N, Stanzione P (1982) Responses of intracellularly recorded cortical neurons to the iontophoretic application of dopamine. Brain Res 245:267-274.

Bischoff S, Heinrich M, Sonntag JM, Krauss J (1986) the D-1 dopamine receptor antagonist SCH 23390 also interacts potently with brain serotonine (5-HT2) receptors. Eur J Pharmacol 129:367-370.

Bischoff S, Heinrich M, Krauss J, Sills MA, Williams M, Vassout A (1988) Interaction of the D1 receptor antagonist SCH 23390 with the central 5-HT system: radioligand binding studies, measurements of biochemical parameters and effects on L-5-HTP syndrome. J Recept Res 8:107-120.

Brady AM, O'Donnell P (2004) Dopaminergic modulation of prefrontal cortical input to nucleus accumbens neurons in vivo. J Neurosci 24:1040-1049.

Bunney BS, Aghajanian GK (1976) Dopamine and norepinephrine innervated cells in the rat prefrontal cortex: pharmacological differentiation using microiontophoretic techniques. Life Sci 19:1783-1789.

Caille I, Dumartin B, Bloch B (1996) Ultrastructural localization of D1 dopamine receptor immonureactivity in rat striatonigral neurons and its relation with dopaminergic innervation. Brain Res 730:17-31.

Carr DB, Sesack SR (2000) GABA-containing neurons in the rat ventral tegmental area project to the prefrontal cortex. Synapse 38:114-123.

Cass WA, Gerhardt GAJ (1995) In vivo assessment of dopamine uptake in rat medial prefrontal cortex: comparison with dorsal striatum and nucleus accumbens. J Neurochem 65:201-207.

Chapman CA, Trepel C, Ivanco TL, Froc DJ, Wilson K, Racine RJ (1998) Changes in field potentials and membrane currents in rat sensorimotor cortex following repeated tetanization of the corpus callosum in vivo. Cereb Cortex 8:730-742.

Chuhma N, Zhang H, Masson J, Zhuang X, Sulzer D, Hen R, Rayport S (2004) Dopamine neurons mediate a fast excitatory signal via their glutamatergic synapses. J Neurosci 24:972-981.

Compte A, Brunel N, Goldman-Rakic PS, Wang XJ (2000) Synaptic mech- anisms and network dynamics underlying spatial working memory in a cortical network model. Cereb Cortex 10:910-923.

Connelly ST, Shepard PD (1997) Competitive NMDA receptor antagonists differentially affect dopamine cell firing patterns. Synapse 25:234-242.

Cragg SJ, Rice ME (2004) DAncing past the DAT at a DA synapse. Trends Neurosci 27:270-277.

Dal Bo G, St-Gelais F, Danik M, Williams S, Cotton M, Trudeau LE (2004) Dopamine neurons in culture express VGLUT2 explaining their capacity to release glutamate at synapses in addition to dopamine. J Neurochem 88:1398-1405.

Daniela E, Brennan K, Gittings D, Hely A, Schenk S (2004) Effect of SCH

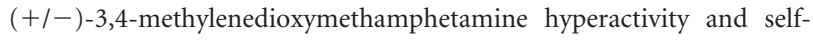
administration in rats. Pharmacol Biochem Behav 44:475-750.

Del Arco A, Mora F (2000) Endogenous dopamine potentiates the effects of glutamate on extracellular GABA in the prefrontal cortex of the freely moving rat. Brain Res Bull 53:339-345.

Descarries L, Lemay B, Doucet G, Berger B (1987) Regional and laminar density of the dopamine innervation in adult rat cerebral cortex. Neuroscience 21:807-824.

Durstewitz D, Seamans JK (2002) The computational role of dopamine D1 receptors in working memory. Neural Netw 15:561-572.

Durstewitz D, Seamans JK, Sejnowski TJ (2000) Dopamine-mediated stabilization of delay-period activity in a network model of prefrontal cortex. J Neurophysiol 83:1733-1750.

Feenstra MG, Botterblom MH (1996) Rapid sampling of extracellular dopamine in the rat prefrontal cortex during food consumption, handling and exposure to novelty. Brain Res 742:17-24.

Feenstra MG, Botterblom MH, van Uum JF (1995) Novelty-induced increase in dopamine release in the rat prefrontal cortex in vivo: inhibition by diazepam. Neurosci Lett 1 89:81-84.

Feenstra MG, Botterblom MH, Mastenbroek S (2000) Dopamine and noradrenaline efflux in the prefrontal cortex in the light and dark period: effects of novelty and handling and comparison to the nucleus accumbens. Neuroscience 100:741-748.

Finlay JM, Zigmond MJ (1997) The effects of stress on central dopaminergic neurons: possible clinical implications Neurochem Res 22:1387-1394.

Finlay JM, Zigmond MJ, Abercrombie ED (1995) Increased dopamine and norepinephrine release in medial prefrontal cortex induced by acute and chronic stress: effects of diazepam et al. Neuroscience 6 4:619-628.

Freeman AS, Bunney BS (1987) Activity of A9 and A10 dopaminergic neurons in unrestrained rats: further characterization and effects of apomorphine and cholecystokinin. Brain Res 405:46-55.

Freeman AS, Meltzer LT, Bunney BS (1985) Firing properties of substantia nigra dopaminergic neurons in freely moving rats. Life Sci 36:1983-1994.

Fremeau Jr RT, Burman J, Qureshi T, Tran CH, Proctor J, Johnson J, Zhang H, Sulzer D, Copenhagen DR, Storm-Mathisen J, Reimer RJ, Chaudhry FA, Edwards RH (2002) The identification of vesicular glutamate transporter 3 suggest novel modes of signaling by glutamate. Proc Natl Acad Sci USA 99:14488-14493.

Fujiyama F, Furuta T, Kaneko T (2001) Immunocytochemical localization of candidates for vesicular glutamate transporters in the rat cerebral cortex. J Comp Neurol 435:379-387.

Garris PA, Collins LB, Jones SR, Wightman RM (1993) Evoked extracellular dopamine in vivo in the medial prefrontal cortex. J Neurochem 61:637-647.

Garris PA Ciolkowski EL, Pastore P, Wightman RM (1994) Efflux of dopamine from the synaptic cleft in the nucleus accumbens of the rat brain. J Neurosci 14:6084-6093.

Gerhardt GA, Cass WA, Hudson J, Henson M, Zhang Z, Ovadia A, Hoffer BJ, Gash DM (1996) In vivo electrochemical studies of dopamine overflow and clearance in the striatum of normal and MPTP-treated rhesus monkeys. J Neurochem 66:579-588.

Godbout R, Mantz J, Pirot S, Glowinski J, Thierry AM (1991) Inhibitory influence of the mesocortical dopaminergic neurons on their target cells: electrophysiological and pharmacological characterization. J Pharmacol Exp Ther 258:728-738.

Goldman-Rakic PS (1995) Cellular basis of working memory. Neuron 14:477-485.

Gorelova NA, Yang CR (2000) Dopamine D1/D5 receptor activation modulates a persistent sodium current in rat prefrontal cortical neurons in vitro. J Neurophysiol 84:75-87.

Gorelova N, Seamans JK, Yang CR (2002) Mechanisms of dopamine activa- 
tion of fast-spiking interneurons that exert inhibition in rat prefrontal cortex. J Neurophysiol 88:3150-3166.

Grace AA (2002) Dopamine. In: Neuropsychopharmacology: the fifth generation of progress (Davis KL, Charney D, Coyle JT, Nemeroff C, eds), pp 120. Baltimore: Lippincott Williams and Wilkins.

Grass C, Herzog E, Bellenchi GC, Bernard V, Ravassard P, Pohl M, Gasnier B, Giros B, El Mestikawy S (2002) A third vesicular glutamate transporter is expresses by cholinergic and serotoninergic neurons. J Neurosci 22:5442-5451.

Gribkoff VK, Ashe JH (1984) Modulation by dopamine of population responses and cell membrane properties of hippocampal CA1 neurons. Brain Res 292:327-338.

Gulledge AT, Jaffe DB (2001) Multiple effects of dopamine on layer V pyramidal cell excitability in rat prefrontal cortex. J Neurophysiol 86:586-595.

Hanley JJ, Bolam JP (1997) Synaptology of the nigrostriatal projection in relation to the compartmental organization of the neostriatum in the rat. Neuroscience 81:353-370.

Hedou G, Homberg J, Feldon J, Heidbreder CA (2001) Expression of sensitization to amphetamine and dynamics of dopamine neurotransmission in different laminae of the rat medial prefrontal cortex. Neuropharmacology 40:366-382.

Henze DA, Gonzalez-Burgos GR, Urban NN, Lewis DA, Barrionuevo G (2000) Dopamine increases excitability of pyramidal neurons in primate prefrontal cortex. J Neurophysiol 84:2799-2809.

Hernandez RV, Derrick BE, Rodriguez WA, Martinez Jr J (1994) (+/-) $\mathrm{CPP}$, and NMDA receptor antagonist, blocks the induction of commissural-CA3 LTP in the anesthetized rat. Brain Res 656:215-219.

Herzog E, Gilchrist J, Gras C, Muzerelle A, Ravassard P, Giros B, Gaspar P, El Mestikawy S (2004) Localization of VGLUT3, the vesicular glutamate transported type 3 in the rat brain. Neuroscience 123:983-1002.

Hochstetler SE, Puopolo M, Gustincich S, Raviola E, Wightman RM (2000) Real-time amperometric measurements of zeptomole quantities of dopamine released from neurons. Anal Chem 72:489-496.

Hollerman JR, Schultz W (1998) Dopamine neurons report an error in the temporal prediction of reward during learning. Nat Neurosci 1:304-309.

Huang YY, Kandel ER (1995) D1/D5 receptor agonists induce a protein synthesis-dependent late potentiation in the CA1 region of the hippocampus. Proc Natl Acad Sci USA 92:2446-2450.

Hyland BI, Reynolds JN, Hay J, Perk CG, Miller R (2002) Firing modes of midbrain dopamine cells in the freely moving rat. Neuroscience 114:475-492.

Ikemoto K, Satoh K, Kitahama K, Geffard M, Maeda T (1996) Electronmicroscopic study of dopaminergic structures in the medial subdivision of the monkey nucleus accumbens. Exp Brain Res 111:41-50.

Johnson MD (1994) Synaptic glutamate release by postnatal rat serotoninergic neurons in microculture. Neuron 12:433-442.

Johnson MD, Yee AG (1995) Ultrastructure of electrophysiologically characterized synapses formed by serotoninergic raphe neurons in culture. Neuroscience 67:609-623.

Joyce MP, Rayport S (2000) Messoaccumbens dopamine neurons synapses reconstructed in vitro are glutamatergic. Neuroscience 99:445-456.

Kitai ST, Sugimori M, Kocsis JD (1976) Excitatory nature of dopamine in the nigro-caudate pathway. Exp Brain Res 24:351-363.

Kimura F, Nishogori A, Shirokawa T, Tsumoto T (1989) Long-term potentiation and $\mathrm{N}$-methyl-D-aspartate receptors in the visual cortex of young rats. J Physiol (Lond) 414:125-144.

Kiyatkin EA (1988) Functional properties of presumed dopaminecontaining and other ventral tegmental area neurons in conscious rats. Int J Neurosci 42:21-43.

Kocsis JD, Kitai ST (1977) Dual excitatory inputs to caudate spiny neurons from substantia nigra stimulation. Brain Res 138:271-283.

Le Moal M, Simon H (1991) Mesocorticolimbic dopaminergic network: functional and regulatory roles. Physiol Rev 71:155-234.

Lewis BL, O'Donnell P (2000) Ventral tegmental area afferents to the prefrontal cortex maintain membrane potential "up" states in pyramidal neurons via D1 dopamine receptors. Cereb Cortex 10:1168-1175.

Li Y, Hu XT, Berney TG, Vartanian AJ, Stine CD, Wolf ME, White FJ (1999) Both glutamate receptor antagonist and prefrontal cortex lesions prevent induction of cocaine sensitization and associated neuroadapatations. Synapse 34:169-180.

Marsteller DA, Gerasimov MR, Schiffer WK, Geiger JM, Barnett CR, Borg JS, Scott S, Ceccarelli J, Volkow ND, Molina PE, Alexoff DL, Dewey SL
(2002) Acute handling stress modulates methylphenidate-induced catecholamine overflow in the medial prefrontal cortex. Neuropsychopharmacology 27:163-170.

Mercuri NB, Bernardi G, Calabresi P, Cotugno A, Levi G, Stanzione P (1985) Dopamine decreases cell excitability in rat striatal neurons by preand post-synaptic mechanisms. Brain Res 358:110-121.

Miller JD, Sanghera MK, German DC (1981) Mesencephalic dopaminergic unit activity in the behaviorally conditioned rat. Life Sci 29:1255-1263.

Moron JA, Brockington A, Wise RA, Rocha BA, Hope BT (2002) Dopamine uptake through the norepinephrine transporter in brain regions with low levels of the dopamine transporter: evidence from knock-out mouse lines. J Neurosci 22:389-395.

Phillips AG, Ahn S, Floresco SB (2004) Magnitude of dopamine release in medial prefrontal cortex predicts accuracy of memory on a delayed response task. J Neurosci 24:547-553.

Phillips PE, Stuber GD, Heien ML, Wightman RM, Carelli RM (2003) Subsecond dopamine release promotes cocaine seeking. Nature 422:614-618

Pirot S, Godbout R, Mantz J, Tassin JP, Glowinski J, Tierrry AM (1992) Inhibitory effects of ventral tegmental area stimulation on the activity of prefrontal cortical neurons: evidence for the involvement of both dopaminergic and GABAergic components. Neuroscience 49:857-865.

Rasmussen K, Strecker RE, Jacobs BL (1986) Single unit response of noradrenergic, serotonergic and dopaminergic neurons in freely moving cats to simple sensory stimuli. Brain Res 369:336-340.

Rosa-Kenig A, Ouotz JK, Rebec GV (1993) The involvement of D1 and D2 dopamine receptors in amphetamine-induced changes in striatal unit activity in behaving rats. Brain Res 619:347-351.

Schafer MK, Varoqui H, Defamie N, Weihe E, Erickson JD (2002) Molecular cloning and functional identification of mouse vesicular glutamate transporter 3 and its expression in subsets of novel excitatory neurons. J Biol Chem 277:50734-50748.

Schultz W (1997) Dopamine neurons and their role in reward mechanisms. Curr Opin Neurobiol 7:191-197.

Schultz W (1998) Predictive reward signal of dopamine neurons. J Neurophysiol 80:1-27.

Seamans JK, Yang CR (2004) The principal features and mechanisms of dopamine modulation in the prefrontal cortex. Prog Neurobiol 74:1-57.

Seamans JK, Durstewitz D, Christie B, Stevens CF, Sejnowski TJ (2001a) Dopamine D1/D5 receptor modulation of excitatory synaptic inputs to layer V prefrontal cortex neurons. Proc Natl Acad Sci USA 98:301-306.

Seamans JK, Gorelova N, Durstewitz D, Yang CR (2001b) Bidirectional dopamine modulation of GABAergic inhibition in prefrontal cortical pyramidal neurons. J Neurosci 21:3628-3638.

Seamans JK, Nogueira L, Lavin A (2003) Synaptic basis of persistent activity in prefrontal cortex. Cereb Cortex 13:1242-1250.

Seguela P, Watkins KC, Descarries L (1988) Ultrastructural features of dopamine axon terminals in the anteromedial and the suprarhinal cortex of adult rat. Brain Res 442:11-22.

Sesack SR, Bunney BS (1989) Pharmacological characterization of the receptor mediating electrophysiological responses to dopamine in the rat medial prefrontal cortex: a microiontophoretic study. J Pharmacol Exp Ther 248:1323-1333.

Sesack SR, Hawrylak VA, Matus C, Guido MA, Levey AI (1998) Dopamine axon varicosities in the prelimbic division of the rat prefrontal cortex exhibit sparse immunoreactivity for the dopamine transporter. J Neurosci 118:2697-2708

Shu Y, Hasenstaub A, Badoual M, Bal T, McCormick DA (2003) Barrages of synaptic activity control the gain and sensitivity of cortical neurons. Neuroscience 23:10388-10401.

Smiley JF, Levey AI, Ciliax BJ, Goldman-Rakic PS (1994) D1 dopamine receptor immunoreactivity in human and monkey cerebral cortex: predominant and extrasynaptic localization in dendritic spines. Proc Natl Acad Sci USA 91:5720-5724.

Staal RG, Mosharov EV, Sulzer D (2004) Dopamine neurons release transmitter via a flickering fusion pore. Nat Neurosci 7:341-346.

Steinfels GF, Heym J, Strecker RE, Jacobs BL (1983) Behavioral correlates of dopaminergic unit activity in freely moving cats. Brain Res 258:217-228.

Strecker RE, Steinfels GF, Jacobs BL (1983) Dopaminergic unit activity in freely moving cats: lack of relationship to feeding, satiety, and glucose injections. Brain Res 260:317-321.

Sulzer D, Joyce MP, Lin L, Geldwert D, Haber SN, Hattori T, Rayport S 
(1998) Dopamine neurons make glutamatergic synpases in vitro. J Neurosci 18:4588-4602.

Taber MT, Fibiger HC (1997) Activation of the mesocortical dopamine system by feeding: lack of a selective response to stress. Neuroscience 77:295-298.

Umemiya M, Raymond LAJ (1997) Dopaminergic modulation of excitatory postsynaptic currents in rat neostriatal neurons. J Neurophysiol 78:1248-1255.

Varela JA, Sen K, Gibson J, Fost J, Abbott LF, Nelson SB (1997) A quantitative description of short-term plasticity at excitatory synapses in layer $2 / 3$ of rat primary visual cortex. J Neurosci 17:7926-7940.

Vives F, Mogenson G (1986) Electrophysiological study of the effects of eth D1 and D2 dopamine anatgonits in the interaction of converging inputs from the sensory-motor cortex and substantia nigra neurons in the rat. Neuroscience 17:349-359.

Watanabe M, Kodama T, Hikosaka K (1997) Increase of extracellular dopamine in primate prefrontal cortex during a working memory task. J Neurophysiol 78:2795-2798.

West AR, Grace AA (2002) Opposite influences of endogenous dopamine $\mathrm{D}_{1}$ and $\mathrm{D}_{2}$ receptor activation on activity states and electrophysiological properties of striatal neurons: studies combining in vivo intracellular recordings and reverse microdialysis. J Neurosci 22:294-304.

Williams GV, Millar J (1990) Concentration-dependent actions of stimu- lated dopamine release on neuronal activity in rat striatum. Neuroscience 39:1-16.

Wilson CJ, Chang HT, Kitai ST (1982) Origins of postsynaptic potentials evoked in identified rat neostriatal neurons by stimulation in subtantia nigra Exp Brain Res 451:157-167.

Yanagihashi R, Yamanouchi K, Ishikawa T (1991) The effects of apomorphine on the hippocampal field potential in freely moving rats: pharmacological evidence of the involvement of D2 receptors. Neuropharmacology 30:177-182.

Yang CR, Seamans JS (1996) Dopamine $\mathrm{D}_{1}$ receptor actions in layer V-VI rat prefrontal cortex neurons in vitro: modulation of dendritic-somatic signal integration. J Neurosci 16:1922-1935.

Yang SN (2000) Sustained enhancement of AMPA receptor- and NMDA receptor-mediated currents induced by dopamine D1/D5 receptor activation in the hippocampus: an essential role of postsynaptic $\mathrm{Ca}^{2+}$. Hippocampus 10:57-63.

Yoshioka M, Matsumoto M, Togashi H, Saito H (1996) Effect of conditioned fear stress on dopamine release in the rat prefrontal cortex. Neurosci Lett 209:201-203.

Yung KK, Bolam JP, Smith AD, Hersch SM, Ciliax BJ, Levey AI (1995) Immuncytochemical localization of D1 and D2 dopamine receptors in the basal ganglia of the rat: light and electron microcopy. Neuroscience 65: $709-730$. 